\title{
Chemical discrimination of pesticide-treated grapes by lizards (Gallotia galloti palmae, Fam. Lacertidae)
}

\author{
Nieves Rosa Yanes-Marichal11, Angel Fermín Francisco-Sánchez¹, Miguel Molina-Borja2,* \\ ${ }^{1}$ Laboratorio de Agrobiología, Cabildo Insular de La Palma. \\ ${ }^{2}$ Grupo Etología y Ecología del Comportamiento, Departamento de Biología Animal, Facultad de Biología, \\ Universidad de La Laguna, 38206 La Laguna, Tenerife, Canary Islands. \\ *Correspondence: Phone: +34 922318341, Fax: +34 922318311, E-mail: mmolina@ull.edu.es
}

Received: 14 November 2016; returned for review: 1 December 2016; accepted 3 January 2017.

Lizards from the Canary Islands may act as pests of several cultivated plants. As a case in point, vineyard farmers often complain about the lizards' impact on grapes. Though no specific pesticide is used for lizards, several pesticides are used in vineyards to control for insects, fungi, etc. We therefore tested whether lizards (Gallotia galloti palmae) could detect and discriminate pesticidetreated from untreated grapes. To answer this question, we performed experiments with adults of both sexes obtained from three localities in La Palma Island. Two of them were a vineyard and a banana plantation that had been treated with pesticides and the other one was in a natural (untreated) site. In the laboratory, lizards were offered simultaneously one untreated (water sprayed) and one treated (with Folithion $50 \mathrm{LE}$, diluted to $0.1 \%$ ) grape placed on small plates. The behaviour of the lizards towards the fruits was filmed and subsequently quantified by means of their tongue-flick, licks or bite rates to each of the grapes. Results showed that only lizards from the natural (untreated) site clearly differentiated the two types of grapes, performing significantly more tongue-flicks, licks and bites to the untreated than to the pesticide-treated grapes. Lizards captured at the other two sites (cultivated fields with pesticide treatment), did not show a significantly different response to the two types of grapes. These results suggest that lizards living in or near cultivated fields may be habituated to pesticide-treated food and, therefore, do not clearly discriminate treated from untreated food items. However, another possibility is that natural selection (or maybe resistance) could be responsible by these individuals in the populations showing this kind of pesticide insensitiveness.

Key words: chemical detection; Gallotia ; grapes; lizards; pesticide.

Impact of wild fauna on crops is a problem documented worldwide (Dolbeer, 1990; Dolbeer et al., 1994; Hill, 1997; Brittingham et al., 2000; Tillman et al., 2000; Avery, 2002; Witmer et al., 2007 ). In the Canary Islands, cultivated plants are affected by a wide variety of animal species, mainly invertebrates (insects and arachnids), but also by several vertebrates such as rats, mice, birds and lizards (Rodríguez-López, 1996). While there is some information on the effects of insects on Canary vineyards (PÉrez-Padrón \& Rodríguez-López, 1987; Lorenzo BethenCOURT et al., 2004), nothing is known on the quantitative effect of vertebrate species 
(indirect estimations appeared in MARquINA, 1977). However, farmers have traditionally complained about damage conducted by several vertebrates, mainly blackbirds and lizards, to several crops including vineyard fields.

Invertebrate pests are usually treated by applying different kinds of pesticides. Folithion 50 LE (the organophosphate Fenitrothion $50 \%$ ) is the acaricidefungicide most commonly used for different plant pests, including those found in vineyards. This pesticide may help to control some insect-arachnid pests, but almost no data exist on its effect on any lizard species (but see Bain et al., 2004). However, other cholinesterase-inhibiting pesticides have been shown to affect physiological/ performance traits in some reptiles (PAULI \& Money, 2000; Hopkins et al., 2005; HopKINS \& WINNE, 2006); on the other hand, while pesticide treatment was shown to affect presence of reptiles in natural areas (LAMBert, 2005), few significant differences were found in populations of $\mathrm{Po}$ darcis bocagei living in agricultural habitats which were either regularly exposed or not to pesticides (Amaral et al., 2012).

La Palma Island has many vineyards with different types of pest treatments. Gallotia galloti palmae lizards are found throughout the island and are, like other Gallotia species, omnivorous (Roca et al. 2005). They consume several wild plant species, including fruits of "balo" (Plocama pendula, Fam. Rubiaceae), leaves and inflorescences of "verode" (Senecio kleinia, Fam. Asteraceae), leaves and flowers of "salado" (Schizogine sericea, Fam. Compositae), flowers of "lavandula" (Lavandula canariensis, Fam. "ahulaga" (Launaea arborescens, Fam. Asteraceae), and petals and fruits of "tunera" (Opuntia dilenii, Fam. Cactaceae) (Molina-Borja, 1981, 1986, 1991; MolinaBorJa \& Barquín, 1986; Molina-BorJa \& Bischoff, 1998). As far as animal prey, these lizards eat beetles, ants, cochineals (Dactylopius coccus), and small Cepaea snails (Molina-Borja \& Bischoff, 1998; Valido et al. 2003).

Gallotia galloti palmae is a medium sized lizard (mean adult male snout-vent length $=102 \mathrm{~mm}$ and body mass $=44 \mathrm{~g}$ ). It has a striking sexual dimorphism with large and robust males with a conspicuous bluecoloured gular skin, and smaller and cryptically coloured females (see Bischoff, 1998 for a detailed description of the species). According to farmers' oral tradition the lizards consume, in addition to grapes, the leaves, flowers or fruits of other cultivated plants such as pumpkins, peppers, and tomatoes.

Squamata typically use their tongue to collect chemicals from the environment, and transfer them to the paired vomeronasal organs located in the roof of the buccal cavity (Burghardt, 1970, 1980; Graves \& Halpern, 1989, 1990). Numerous publications have documented the lizards' capacity to detect chemical products produced by plants and other animals (conspecifics or predators) (COOPER, 1989, 1994a,b; FonT, 1996; Cooper \& Pérez-Mellado, 2001a; Cooper et al., 2002; Font \& Desfilis, 2002). Therefore, lizards have the ability to detect (sense) chemical products from several origins, both natural and artificial. As vineyards are commonly treated with pesticides, we therefore hypothesized that lizards could detect and differentiate pesti- 
cide-treated from untreated grapes.

The specific objectives of the present paper are: 1) to determine experimentally if lizards of both sexes of G. g. palmae are capable of discriminating between untreated and pesticide-treated grapes by comparing the behaviour patterns directed towards both types of grapes; 2) Compare the rates of behaviour patterns directed to the grapes by lizards coming from sites with pesticide-treated crops with those of individuals coming from a natural site without any pesticide treatment.

\section{Materials and Methods}

\section{Study zones and capturing method}

We selected three sites to collect lizards for the experiments. One was very close (< $10 \mathrm{~m}$ ) to a banana plantation in Tazacorte (28 $37^{\prime} 36.42^{\prime \prime} \mathrm{N}, 17^{\circ} 55^{\prime} 06.08^{\prime \prime} \mathrm{W}$; altitude: $184.9 \mathrm{~m}$ ), another was inside a vineyard at Fuencaliente ( $28^{\circ} 30^{\prime} 26.98^{\prime \prime}$ N, $17^{\circ}$ $49^{\prime} 23.66^{\prime \prime} \mathrm{W}$; altitude: $639.5 \mathrm{~m}$ ) with volcanic lapilli as substrate, and the third was a natural site at Tigalate (28을 $32^{\prime} 59.01^{\prime \prime} \mathrm{N}$, $17^{\circ} 48^{\prime} 10.19^{\prime \prime} \mathrm{W}$; altitude: $608.7 \mathrm{~m}$ ). The first two sites were inside or in the vicinity of cultivated fields (where pesticides are commonly applied), while the third locality was far away from any pesticide-treated crop. The main vegetation of the last site was composed of: "cerrillo" (Hyparrhenia hirta), "higuerilla" (Euphorbia obtusifolia), and "verode" (Klenia neriifolia). Lizards were collected during June and July of 2002.

Adult individuals of both sexes of G. $g$. palmae were captured with 51 can traps baited with pieces of banana and tomato that were washed with running water before putting them into the cans.

\section{Lizard maintenance}

The animals were transported to the laboratory were they were housed individually in plastic cages with a 12L-12D lightdark cycle provided by daylight fluorescent lamps (including the near ultraviolet spectrum; Sylvania Reptistar 18W Havells-Sylvannia, Erlangen, Germany), and room/ambient temperature of $28 \pm$ $1^{\circ} \mathrm{C}$. Our previous long experience with lizards kept in captivity, has shown that individuals only eat at most two times a week, even when continuously provided with food. Therefore, in order to ensure adequate feeding motivation during the experimental trials, lizards were kept without food for 7 days before beginning the experiments. Immediately after the trials, all lizards were allowed to eat pieces of banana or tomato placed in their individual cages.

\section{Experimental procedure}

Experiments were conducted in an experimental cage $(100 \times 100 \times 80 \mathrm{~cm}$, with a cork plate as substrate) with the same lighting and temperature regime as the maintenance cages, and two small glass dishes placed near one of the cage walls, $30 \mathrm{~cm}$ apart. We put a single untreated grape in one dish and a grape treated with a solution of Folithion 50 LE $^{\circledR}$ (Bayer Cropscience, Ltd., Spain; composition: Fenitrothion $50 \% \mathrm{p} / \mathrm{v}$ ) in the other. We could not access to data on usual pesticide concentrations for treating crops; moreover, as we tried to avoid causing any harm to the experimental lizards, and as our aim for this work was to determine if lizards could respond even to very low levels of pesticide, we diluted Folithion with distilled 
water to $0.1 \%$. Both grapes had been previously washed in running water and then dried. The pesticide was applied to one grape of every pair with a small brush immersed once in the Folithion solution (while the control grape was similarly brushed with distilled water). We used two different grapes of similar size/weight for each experimental trial and we decided by flipping a coin which dish (right or left) would have the treated grape.

Each experimental lizard was placed at the end of the cage opposite that holding the grapes and we filmed its behaviour during at least $20 \mathrm{~min}$ after it resumed spontaneous activity. Filming was performed with a video camera Panasonic NV -DS15, mini DV (Panasonic, Kadoma, Osaka, Japan) placed outside the transparent plastic wall of the cage that was closer to the dishes with the grapes. The whole set up was visually isolated from the rest of the room by a movable screen. Temperature inside the cage ( $1 \mathrm{~cm}$ above substrate) was measured with a digital thermometer $\left(0.1^{\circ} \mathrm{C}\right.$ precision $)$ at the beginning of each experimental session. After each trial, the bottom and walls of the cage were thoroughly cleaned with alcohol $(70 \%)$ and allowed to dry for $10 \mathrm{~min}$. The minimum interval between successive trials was 15 min and all trials were performed between 11:00 and 13:00; each lizard was tested only once.

We set up three experimental groups: 1) lizards that were captured very close to the banana plantation of Tazacorte $(\mathrm{N}=$ $36)$; 2) those from the vineyard of Fuencaliente $(\mathrm{N}=33)$; 3) animals captured at the natural site of Tigalate $(\mathrm{N}=29)$. For all individuals we measured their snout-to- vent length (SVL) and took their body mass (BM) after the trials. All animals were adults as their SVL was similar to or larger than size at sexual maturity (Molina-Borja \& Rodríguez-Domínguez, 2004). Only in very few cases some experimental animals ate only a piece of a Folithion-treated grape. In these cases we checked if the animals did not show any symptoms of illness during the following days. After finishing the experiments, all lizards were released at their capture sites.

\section{Data and Statistics}

From the recorded videos we quantified three behaviour patterns performed by the lizards towards the grapes: tongueflicks, licks and bites (full descriptions in Molina-Borja, 1981, 1987 ). As the duration of trials was around $20 \mathrm{~min}$, we calculated the relative frequency (rate) of each behaviour pattern dividing the number of times it occurred by the exact duration of each trial. In some trials, individuals did not direct at least one tongue-flick, lick or bite to one of the two grapes and were not included in the analyses; this resulted in a smaller sample size for the corresponding statistical comparisons.

Data were analysed with the SPSS $20.0^{\circledR}$ statistical package (Armonk, New York, USA). As variable distributions did not fulfil normality and homoscedasticity requirements, we used Wilcoxon and Kruskal-Wallis tests (Siegel \& Castellan, 1988) to compare the rates of behaviour patterns directed to the two types of grapes within and between populations, respectively. We verified that small differences in cage temperature among trials did not affect rates of the selected behaviour patterns 
Table 1: Mean ( \pm SE) values, range (minimum, maximum) and sample size $(\mathrm{N})$ for male $(\mathrm{m})$ and female (f) Snout-to-vent length (SVL) and Body mass (BM) of the three populations sampled.

\begin{tabular}{|c|c|c|c|c|c|c|c|}
\hline & & \multicolumn{2}{|c|}{ Fuencaliente } & \multicolumn{2}{|c|}{ Tazacorte } & \multicolumn{2}{|c|}{ Tigalate } \\
\hline & & $\mathbf{m}$ & $\mathrm{f}$ & $\mathbf{m}$ & $\mathrm{f}$ & m & $\mathrm{f}$ \\
\hline \multirow[t]{5}{*}{ SVL } & Mean & 100.30 & 80.98 & 104.97 & 87.65 & 96.31 & 83.15 \\
\hline & S.E. & 6.26 & 5.60 & 7.99 & 8.22 & 7.32 & 5.91 \\
\hline & Minimum & 87.99 & 68.65 & 90.23 & 69.75 & 85.67 & 72.53 \\
\hline & Maximum & 108.94 & 93.34 & 120.38 & 100.04 & 105.40 & 92.44 \\
\hline & $\mathrm{N}$ & 16 & 17 & 18 & 18 & 15 & 14 \\
\hline \multirow[t]{5}{*}{$\mathrm{BM}$} & Mean & 54.50 & 54.50 & 42.27 & 23.0 & 33.06 & 22.92 \\
\hline & S.E. & 5.79 & 4.17 & 11.75 & 6.25 & 5.81 & 3.81 \\
\hline & Minimum & 43.0 & 36.0 & 19.0 & 13.0 & 24.0 & 17.0 \\
\hline & Maximum & 61.0 & 51.0 & 67.0 & 37.0 & 41.0 & 30.0 \\
\hline & $\mathrm{N}$ & 16 & 17 & 18 & 18 & 15 & 14 \\
\hline
\end{tabular}

and compared relative frequencies of those performed by the lizards towards the untreated and Folithion-treated grapes. We also tested for differences in body size (SVL) of lizards from the three populations and did not detect any significant difference (Bonferroni and Tukey post -hoc pair-wise comparisons; $P>0.05$ in all cases). Rates of the three selected behaviour patterns were not significantly different (Mann-Whitney $U$ test) for males and females from any site $(P>0.01$ in all cases); therefore, we pooled data from both sexes of each site in order to make the statistical comparisons of behaviour patterns directed towards each type of grape. We set $a l p h a=0.05$, significance tests were two-tailed and we applied Sidak correction for multi- ple tests when appropriate (Wright 1992).

\section{Results}

Mean ( \pm SE, range and sample size) of SVL and BM for males and females used in the experiments are shown in Table 1.

There was no significant relationship between substrate temperatures inside the experimental cage and the rates at which the lizards performed the three behaviour patterns $(\mathrm{rho}=0.20, P=0.28$; rho $=-0.27, P$ $=0.20$; and rho $=0.22, P=0.39$; for tongueflicks, licks and bites, respectively, $\mathrm{N}=29$ in all cases).

Lizards captured at Fuencaliente performed significantly more tongue-flicks to the untreated than to the treated grapes (Wilcoxon tests, $\mathrm{Z}=-2.189, \mathrm{~N}=31, P=$ 


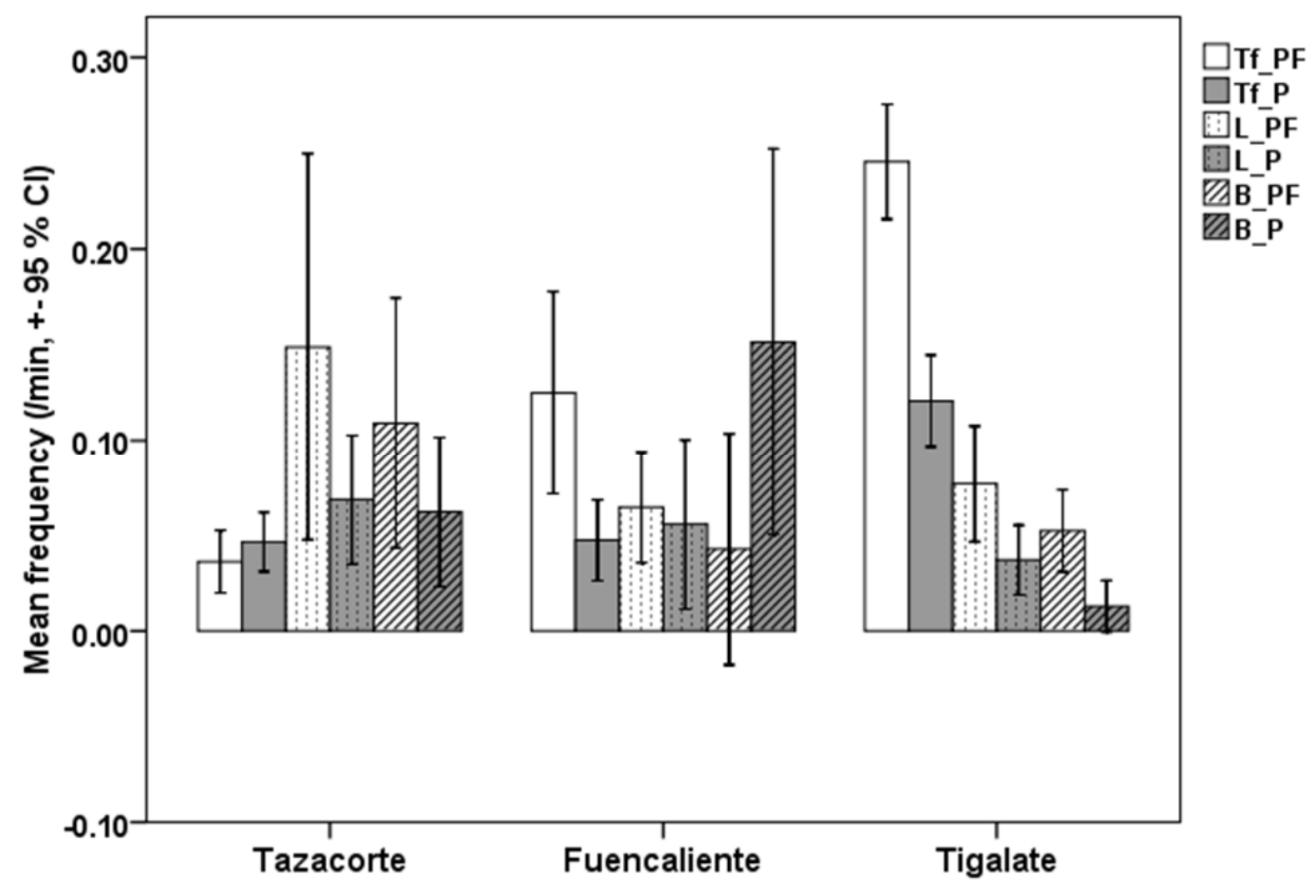

Figure 1: Mean $( \pm 95 \% \mathrm{CI})$ relative frequencies of tongue-flicks (Tf), licks (L) and bites (B) of experimental lizards from Tazacorte, Fuencaliente and Tigalate towards untreated (PF) and pesticide-treated $(\mathrm{P})$ grapes.

0.029), but there was no difference in their licks $(Z=-0.731, N=19, P=0.46)$, or bites ( $Z=-1.364, N=7, P=0.174)$ (Fig. 1).

On the other hand, lizards captured at Tazacorte did not show any significant difference in their rates of behaviour toward the treated and untreated grapes (tongue-flicks, $Z=-0.778, N=32, P=0.437$; licks, $\mathrm{Z}=-1.178, \mathrm{~N}=25, P=0.239$; bites, $\mathrm{Z}$ $=-1.50, \mathrm{~N}=21, P=0.33$, Fig. 1 ).

Lizards captured at Tigalate directed significantly more tongue-flicks $(Z=-$ 4.371, $\mathrm{N}=29, P=0.0001)$, licks $(Z=-2.574$, $\mathrm{N}=24, P=0.01)$, and bites $(\mathrm{Z}=-2.255, \mathrm{~N}=$ $17, P=0.02)$, at the untreated than at the treated grapes (Fig. 1).

On the other hand, rates of behaviour patterns directed at untreated grapes differed (alpha $=0.025$ after Sidak correction) among lizards from the three sites. Thus, lizards from Tigalate performed more tongue-flicks than those of Fuencaliente and Tazacorte (Kruskal-Wallis test, chi-square $=50.66$, d.f. $=2, P<0.0001)$. However, there was no significant difference in the frequencies of licks or bites to the untreated grapes by lizards from the three sites. In the case of pesticide-treated grapes, lizards from Tigalate again tongue -flicked significantly more often than those from Fuencaliente and Tazacorte (KruskalWallis test, chi-square $=22.83$, d.f. $=2, P<$ 0.0001) while those from Fuencaliente bit significantly more than those of Tazacorte and Tigalate (Kruskal-Wallis test, chisquare $=8.30$, d.f. $=2, P=0.016)$; there was 
no significant difference in the rates of licking among lizards from the three sites.

The number of lizards that actually bit pesticide-treated grapes or the untreated ones were, respectively, five and two (Fuencaliente), four and 15 (Tigalate) and 10 and 14 (Tazacorte).

\section{Discussion}

It has been noted that while differential tongue-flick rates may indicate discrimination, their absence does not necessarily indicate lack of discriminatory ability (see CoOper 1998). However, the number of bites in each of our experimental conditions seems to support a lack of discrimination by G. g. palmae lizards from pesticidetreated areas. On the contrary, lizards from the untreated site had the ability to discriminate Folithion-treated from untreated grapes. Specifically, lizards from sites were pesticides are used did not significantly differ in their behaviour towards untreated and treated grapes, the only exception being the larger number of tongue-flicks directed by lizards from Fuencaliente to untreated than to treated grapes. There is no clear explanation for this difference (though the statistic value found, $P=0.029$, could well be a false positive) nor for the higher frequency of biting treated grapes by lizards from Fuencaliente in comparison with those of Tazacorte; a potential explanation could be related with a difference in water supply in these two sites. In the second location there were some open sewage pipes and water leaks from some pipes while in the first site there was a complete absence of water sources. This last fact would imply that, previously to their capture, lizards from Fuencaliente could have been more water-deprived than those of Tazacorte and then be more prone to consume the grapes.

On the other hand, lizards from the untreated site tongue-flicked, licked and bit untreated grapes more often than treated grapes. These results seem to indicate that lizards that inhabit natural areas, without previous contact with pesticidetreated crops, have the ability to discriminate between pesticide-treated and untreated fruits.

Several lizard species, including the Canarian lizards of the genus Gallotia, have been shown to respond with tongueflicks to sugar, fat and also to toxins of several plants (COOper, 1994a,b; CoOper \& Pérez-Mellado, 2001a,b,c; Cooper et al., 2002), but this is the first time a lizard is shown to chemically discriminate the presence of pesticide on a fruit.

Does this imply that the application of non-specific pesticides could contribute to reduce the rate of consumption of pesticide-treated fruits by lizards? We cannot currently answer this question as field behavioural analyses are needed to compare rates of tongue-flicks, licks or bites to pesticide-treated and untreated grapes (or other fruits or plant items). Our results suggest that, after continuous pesticide treatment on crops, the surviving lizards could become habituated or somehow handicapped in their chemosensory abilities, and therefore not be able to discriminate pesticide-treated from untreated fruits or consume them differentially. Alternatively, lizards could have been selected for pesticide resistance. However, to disentangle between acclimation and selection, a common garden experiment would be needed. 
In fact, lizards from one of the pesticidetreated sites (Fuencaliente) significantly bit more pesticide-treated grapes than individuals from the other two sites.

It is possible that lizards from pesticide -treated crops could have some of its sensory/brain functions affected from previous ingestion of pesticide-treated fruit and, therefore, would not be able to differentiate treated from untreated grapes. There are data on several possible contaminants for reptiles (CAmpbell \& CAmpbell, 2000, 2002; Pauli \& Money, 2000) and Carbamate and other organophosphate-based pesticides are known to inhibit brain acetylcholinesterase activity (HALl \& ClarK, 1982; Russell \& Overstreet, 1987). For example, a reduction in swimming performance was detected in cholinesteraseinhibiting pesticide treated natricine snakes (Hopkins \& Winne, 2006). However, low doses of Fenitrothion did not have any significant effect on several physiological and behavioural parameters of the agamid Pogona vitticeps (BAIN et al., 2004), nor were these traits affected by low doses of carbaryl (a carbamate pesticide) in Sceloporus occidentalis (DuRANT, 2006).

Another possibility is that lizards may learn to avoid the consumption of certain foods if associated with illness. Thus, for example, Burghardt et al. (1973) could induce aversion to palatable prey by delayed illness in garter snakes, and PARAdis \& CABANAC (2004) found flavour aversion learning in several basilisks and skink species when injected with lithium chloride (an illness inducer) after consuming novel food. However our data do not support this hypothesis as some experimental lizards from pesticide-treated areas did in fact lick or bite pesticide-treated grapes. This result poses two suggestions: 1) that vineyards treated with Fenitrothion might not have an effect on consumption of grapes by lizards; 2) the consumption of pesticide-treated grapes could induce some organism dysfunction in lizards (see above); this last effect could then affect conservation of populations living in or near crops and their predators.

On the other hand, most individuals from the natural zone (Tigalate) avoided consuming pesticide-treated grapes: 15 lizards from that location bit the untreated grape compared to only four that bit the pesticide-treated grape. This suggests that lizards not previously having experience of pesticide-treated foods could avoid eating them; only after reiterated pesticide treatments of a zone, they could become habituated.

\section{Acknowledgement}

We thank Enrique Font for a detailed revision of an earlier version of the manuscript. To Consejería de Agricultura, Ganadería y Pesca from Cabildo Insular de La Palma (island institution) that funded the study; we are especially indebted to the deceased Margarita Castro, former director of that Consejería. We also thank the staff of Laboratorio de Agrobiología for their support during the experimental work. To the offices of Extensión Agraria in La Palma for their cooperation providing information on common pests and pesticides in the Island. Consejería de Medio Ambiente of Cabildo de La Palma provided the permissions to capture the lizards (given by a decree of Cabildo de La Palma, dated $22^{\text {nd }}$ February 2000). For the experi- 
mental work, we followed the corresponding regulation and legislation on animal care.

\section{REFERENCES}

Amaral, M.J.; Carretero, M.A.; Bicho, R.C.; SoAres, A.M.V.M. \& Mann, R.M. (2012). The use of a lacertid lizard as a model for reptile ecotoxicology studies: Part 1 - Field demographics and morphology. Chemosphere, 87: 757-764.

Avery, M.L. (2002). Behavioral and Ecological Considerations for Managing Bird Damage to Cultivated Fruit, In D.J Lever; W.R. Silva \& M. Galetti (eds.) Seed Dispersal and Frugivory: Ecology. Evolution and Conservation. CABI Publishing, New York, USA, pp. 467477.

Bain, D.; Buttemer, W.A.; Astheimer, L.; FilDES, K. \& Hooper M.J. (2004). Effects of sublethal fenitrothion ingestion on cholinesterase inhibition, standard metabolism, thermal preference, and prey-capture ability in the Australian central bearded dragon (Pogona vitticeps, Agamidae). Environmental Toxicology \& Chemistry 23: 109-116.

Bischoff, W. (1998). Handbuch der reptilien und amphibien Europas. Band 6: Die reptilien der Kanarischen inseln, der Selvagens-Inseln und des Madeira-Archipels. Wiesbaden:AULAVerlag, Berlin, Germany.

Brittingham, M.C.; Kays, J. \& McPeake, R. (2000). Proceedings of the Ninth Wildlife Damage Management Conference. State College, PA, USA.

Burghardt, G.M. (1970). Chemical perception in reptiles, In J.W. Johnston; D.G. Moulton \& A. Turk (eds.) Advances in Chemoreception, Vol. 1, Communication by Chemical Signals. Appleton-Century-Crofts, New York, pp. 241-308.

Burghardt, G.M. (1980). Behavioral and stimulus correlates of vomeronasal functioning in reptiles: feeding, grouping, sex, and tongue use, In D. MülLER-SchwARZE \& R.M. SilverSTEIN (eds.) Chemical signals, vertebrates and aquatic invertebrates. Plenum Press, New York, London, pp. 275-301.

Burghardt, G.M.; Wilcoxon, H.C. \& Czaplicki, J.A. (1973). Conditioning in garter snakes: Aversion to palatable prey induced by delayed illness. Animal Learning and Behavior 1: 317-320.

Campbell, K.R. \& Campbell, T.S. (2000). Lizard contaminant data for ecological risk assessment. Reviews of Environmental Contamination and Toxicology 165: 39-116.

Campbell, K.R. \& Campbell, T.S. (2002). A logical starting point for developing priorities for lizard and snake ecotoxicology: a review of available data. Environmental Toxicology and Chemistry 21: 894-898.

Cooper, W.E.JR. (1989). Prey odor discrimination in the varanoid lizards Heloderma suspectum and Varanus exanthematicus. Ethology 81: 250-258.

Cooper, W.E.Jr. (1994a). Chemical discrimination by tongue-flicking in lizards: a review with hypotheses on its origin and its ecological and phylogenetic relationships. Journal of Chemical Ecology 20: 439-487.

Cooper, W.E.JR. (1994b). Multiple functions of extraoral lingual behaviour in iguanian lizards: prey capture, grooming and swallowing, but not prey detection. Animal Behaviour 47: 765-775.

Cooper, W.E.JR. (1998). Evaluation of swab and related tests for responses by squamates to chemical stimuli. Journal of Chemical Ecology 24: 841-866.

Cooper, W.E.JR. \& Pérez-Mellado, V. (2001a). Food chemical cues elicit general and population-specific effects on lingual and biting behaviors in the lacertid lizard Podarcis lilfordi. Journal of Experimental Zoology 290: 207-217.

Cooper, W.E.JR. \& Pérez-Mellado, V. (2001b). Location of fruit using only airborne odor cues by a lizard. Physiology \& Behavior 74: 339-342.

Cooper, W.E.Jr. \& Pérez-Mellado, V. (2001c). Chemosensory responses to sugar and fat 
by the omnivorous lizard Gallotia caesaris with behavioral evidence suggesting a role for gustation. Physiology \& Behavior 73: 509-516.

Cooper, W.E.Jr.; Pérez-Mellado, V.; Vitt, L.J. \& Budzinsky, B. (2002). Behavioral responses to plant toxins by two omnivorous lizard species. Physiology \& Behavior 76: 297-303.

Dolbeer, R.A. (1990) Ornithology and integrated pest management: red- winged blackbirds Agelaius phoeniceus and corn. Ibis 132: 309-322.

Dolbeer, R.A.; Holler, N.R. \& Hawthorne, D.W. (1994). Identification and assessment of wildlife damage: an overview, In S.E. Hygnstrom; R.M. Timm \& G.E. Larson (eds.) Prevention and Control of Wildlife Damage. University of Nebraska-Lincoln, USA, pp. A1-A18.

DuRANT, S.E. (2006). Sublethal effects of an acetylcholinesterase-inhibiting pesticide on fitnessrelated traits in the western fence lizard (Sceloporous occidentalis). Ph.D. Dissertation. University of Virginia, USA.

Font, E. (1996). Los sentidos químicos de los reptiles. Un enfoque etológico, In F. ColmeNARES (ed.) Etología, psicología comparada y comportamiento animal. Editorial Síntesis, Madrid, pp. 196-288.

Font, E. \& Desfilis, E. (2002). Chemosensory recognition of familiar and unfamiliar conspecifics by juveniles of the Iberian wall lizard Podarcis hispanica. Ethology 108: 319330.

Graves, B. \& Halpern, M. (1989). Chemical access to the vomeronasal organs of the lizard Chalcides ocellatus. Journal of Experimental Zoology 249: 150-157.

Graves, B. \& Halpern, M. (1990). Roles of vomeronasal organ chemoreception in tongue flicking, exploratory and feeding behaviour of the lizard Chalcides ocellatus. Animal Behaviour 39: 692-698.

Hall, R.J. \& Clark, D.R. JR. (1982). Response of the iguanid lizard Anolis carolinensis to four organophosphorus pesticides. Envi- ronmental Pollution 28: 45-52.

Hill, C.M. (1997). Crop-raiding by wild vertebrates: the farmer's perspective in an agricultural community in western Uganda. International Journal of Pest Management 43: 77-84.

Hopkins, W.A.; Winne, C.T. \& DuRant, S.E. (2005). Differential swimming performance of two natricine snakes exposed to a cholinesterase-inhibiting pesticide. Environmental Pollution 133: 531-540.

Hopkins, W.A., \& Winne, C.T. (2006). Influence of body size on swimming performance of four species of neonatal natricine snakes acutely exposed to a cholinesteraseinhibiting pesticide. Environmental Toxicology \& Chemistry 25: 1208-1213.

LAMbert, M.R.K. (2005). Lizards used as bioindicators to monitor pesticide contamination in sub-Saharan Africa: A review. Applied Herpetology 2: 99-107.

Lorenzo Bethencourt, C.D.; Prendes Ayala, C.; Alvarez de la Paz, F.J.; Cabrera Pérez, R. \& Prendes Lorenzo, C.D. (2004). Distribución y daños producidos por Stenidea annulicornis (Brullé 1838) (Coleoptera: Cerambycidae) en los viñedos de Tacoronte. Tenerife. Canarias, In XI Congreso Ibérico de Entomología (Funchal (Madeira), - Portugal, Septiembre 2004.

Marquina, T. (1977). Los lagartos (Lacerta sp.), una plaga de algunos cultivos de las Islas Canarias. Anales del Instituto Nacional de Investigaciones Agrarias. Serie Proteccion Vegetal: 1-3.

Molina-BorJa, M. (1981). Etograma del lagarto de Tenerife, Gallotia galloti galloti (SauriaLacertidae). Doñana Acta Vertebrata 8: 43-78.

Molina-Borja, M. (1986). Notes on the diet of Gallotia stehlini as obtained from behaviour observations. Vieraea 16: 23-26.

Molina-Borja, M. (1987). Additions to the ethogram of the lizard Gallotia galloti from Tenerife, Canary Islands. Vieraea 17: 171178.

Molina-BorJa, M. (1991). Notes on alimentary 
habits and spatial-temporal distribution of eating behaviour patterns in a natural population of lizards (Gallotia galloti). Vieraea 20: 1-9.

Molina-Borja, M. \& Barquín, E. (1986). On the consumption of Launaea arborescens flowers by the lizard Gallotia atlantica. Vieraea 16: 233-236.

Molina-Borja, M. \& Bischoff, W. (1998). Gallotia galloti, (Oudart, 1839) Kanareneidechse, In W. Bischoff (ed.). Handbuch der Reptilien und Amphibien Europas, Band 6, Aula-Verlag, Wiesbaden, Germany, pp. 287-339.

Molina-Borja, M. \& Rodríguez-Domínguez, M.A. (2004). Evolution of biometric and lifehistory traits in lizards (Gallotia) from the Canary Islands. Journal of Zoological Systematics and Evolutionary Research 42: 44-53.

Pauli, B.D. \& Money, S. (2000). Ecotoxicology of pesticides in reptiles, In D.W. Sparling; G. Linder \& C.A. Bishop (eds.) Ecotoxicology of Amphibians and Reptiles, SETAC Press, Pensacola (FL), USA, pp. 269-324.

Pérez-Padrón, F. \& Rodríguez-López, P. (1987). Observaciones sobre la biología, fenología y daños en la vid de dos especies de curculiónidos del género Laparocerus en la isla de Tenerife. Boletín de Sanidad Vegetal 13: 361-364.

Roca, V.; Carretero, M.A.; Llorente, G.A.; Montori, A. \& Martin, J.E. (2005): Helminth communities of two lizard populations (Lacertidae) from Canary Islands (Spain). Host diet-parasite relation- ships. Amphibia-Reptilia, 26: 535-542.

Rodríguez-López, P. (1996). Plagas y enfermedades de la vid en Canarias. Gobierno de Canarias, Consejería de Agricultura, Ganadería, Pesca y Alimentación, Spain.

Russell, R.W. \& Overstreet, D.H. (1987). Mechanisms underlying sensitivity to organophosphorus anticholinesterase compounds. Progress in Neurobiology 28: 97129.

Siegel, S. \& Castellan, N.J. (1988). Nonparametric Statistics for the Behavioral Sciences, $2^{\text {nd }} \mathrm{ed}$. McGraw-Hill, New York, USA.

Tillman, E.A.; Van Doom, A. \& Avery, M.L. (2000). Bird damage to tropical fruit in South Florida, In M.C. Brittingham; J. Kays \& R. McPeake (eds.) The Ninth Wildlife Damage Management Conference Proceedings. Pennsylvania State College, Pennsylvania, USA, pp. 47-49.

Valido, A.; Nogales, M. \& Medina, F.M. (2003). Fleshy fruits in the diet of Canarian lizards Gallotia galloti (Lacertidae) in a xeric habitat of the Island of Tenerife. Journal of Herpetology 37: 741-747.

Wittner, G. (2007). The ecology of vertebrate pests and integrated pest management (IPM), In M. Kogan \& P. Jepson (eds) Perspectives in Ecological Theory and Integrated Pest Management. Cambridge University Press, Cambridge, UK, pp. 393-410.

Wright, S.P. (1992). Adjusted P-values and simultaneous inference. Biometrics 48: 10051013. 